\title{
GENE ACTION STUDIES IN UPLAND BT COTTON FOR FIBER QUALITY CHARACTERS UNDER WATER-DEFICIT ENVIRONMENT
}

\author{
Sohail Kamaran ${ }^{1, *}$, Tariq Manzoor Khan ${ }^{1}$, Amir Shakeel ${ }^{1}$ and Rashid Ahmad $^{2}$ \\ ${ }^{1}$ Department of Plant Breeding and Genetics, University of Agriculture Faisalabad, Pakistan; ${ }^{2}$ Department of \\ Agronomy, University of Agriculture Faisalabad, Pakistan. \\ *Corresponding author's e-mail: sohailkamransial@gmail.com
}

Genetic effects on fiber quality parameters in six basic populations $\left(\mathrm{P}_{1}, \mathrm{P}_{2}, \mathrm{~F}_{1}, \mathrm{~F}_{2}, \mathrm{BC}_{1}\right.$ and $\left.\mathrm{BC}_{2}\right)$ of crosses viz. TARZAN-1× CIM-602 and A-555×FH-114 were investigated through GMA. The outcomes of the current study envisaged that additive and dominant alongside non-allelic interactions assumed a significant role for the attributes like fiber length and fiber maturity in both crosses, however, additive genetic actions [d] were observed to be imperative for fiber uniformity, fineness and bundle strength. Epistatic gene interactions were present almost in all the quality traits in one or other cross, whereas linkage was prominently observed in bundle strength and fineness. All the fiber traits showed high genetic variance and genetic advance except fiber length where genetic gain was relatively low under normal and water stressed conditions. Inverse indication of [h] and [i] anticipated duplicate genes in the legacy of fiber fineness and length that will bring plant breeders in trouble during selection. Hence, heterosis breeding would be a better choice because complementary gene interaction was absent in all quality traits.

Keywords: BT cotton, gene action, drought, fiber characters, conventional breeding.

\section{INTRODUCTION}

Cotton (Gossypium hirsutum L.) is an important fiber crop that runs the textile sector having 1.4 percent share in GDP and 6.7 percent in agriculture value addition. Pakistan has experienced considerable fluctuations in cotton yield over the last three decades due to the non-availability of water. During 2014-15 cotton showed an abrupt decline in production which led the country to import 345.363 thousand tons raw cotton to meet the needs of textile sector (GOP, 2016-17). The chronological order of irrigation water availability showed a significant decline from year 2001 (103.5 million acre feet) to 2013 (89.6 MAF) (GOP, 2013-14).

Literature available on this aspect of cotton crop showed that variations in bundle length, fiber strength, fiber fineness, fiber maturity and fiber uniformity were provoked by both additive and non-additive genes. Previously, Mert et al. (2003) showed that when additive gene effects are larger in magnitude than non-additive, improvement is possible at early segregating generations but if the magnitude of non-additive is greater than additive, selection is delayed to late segregation generations. Singh and Chahal (2005) studied genetic effects of fiber fineness in 34 cotton crosses and found additive with predominant gene actions. Minhas et al. (2008) also found additive and incomplete dominance effects in all the fiber traits. Desalegn et al. (2009) examined $15 \mathrm{~F}_{1}$ cotton crosses in the field to figure out pattern of inheritance in fiber characteristics and concluded high heritability coupled with high genetic advance for the attributes. Imran et al. (2011) examined hereditary impacts of fiber quality attributes in five upland cotton lines and demonstrated that fiber quality was controlled by additive genetic effects. Saleem et al. (2015) assessed gene action of lint quality parameters of a cross and found additive, dominant and non-allelic interactions in fiber length, strength and fineness. Cotton production puts an extra burden on water resources of the countries where it is grown and processed. Globally, freshwater resources are becoming limited and the quality of water is also reducing. Both biotic and abiotic stresses have unpleasant effect on crop production causing substantial loss of yield and quality worldwide (Bita et al., 2013). It is predicted through climate models that severity and frequency of drought spells will increase under the ongoing global climate change scenarios (Lambers et al., 2008; Walter and Ron, 2011). Present scenarios of global warming have caused shortfall in precipitation (meteorological drought) whereas evapotranspirational water losses have increased that is leading towards agricultural drought (Mishra et al., 2010). Agricultural drought has put normal plant growth and development under danger (Manivannan et al., 2008). This threatening condition has compelled the plant breeders to breed such varieties that can cope with water stressed conditions without sacrificing fiber yield and quality. For this purpose, presence of genetic variability in the breeding material is prerequisite for a successful crop improvement program. To determine the extent of variability, knowledge about heritability, genetic advance and the type of gene action are crucial to predict the behavior of parents and then its utilization in a population 
improvement program. Hence, plant breeders can breed cultivars having better fiber quality under water scarce conditions. Keeping in view the importance of cotton crop and water shortage in the country, present investigations were carried out to study the inheritance pattern of fiber quality traits in the six basic populations of two upland BT cotton crosses under water limiting environments.

\section{MATERIALS AND METHODS}

Development of genetic material: Present investigations were started with the selection of four parental BT cotton genotypes, two drought tolerant (CIM-602 and FH-114) and two drought sensitive (TARZAN-1 and A-555) during 201314. The selected genotypes/cultivars were grown in the field to develop F1s (TARZAN-1 $\times$ CIM-602 and A-555 $\times$ FH114). On October 20, 2014, F1 generations along with their parents were grown in the greenhouse and crosses were made to develop back cross $\left(\mathrm{BC}_{1}\right.$ and $\left.\mathrm{BC}_{2}\right)$ and $\mathrm{F}_{2}$ generations.

Evaluation of the genetic material: During normal cotton growing season 2015-16, populations viz $\mathrm{P}_{1}$ (drought sensitive parent), $\mathrm{P}_{2}$ (drought tolerant parent), $\mathrm{F}_{1} \mathrm{~s}$ (TARZAN$1 \times$ CIM-602 and A-555 $\times$ FH-114), BC $1\left(\mathrm{~F}_{1} \times\right.$ TARZAN-1 and $\left.\mathrm{F}_{1} \times \mathrm{A}-555\right), \mathrm{BC}_{2}\left(\mathrm{~F}_{1} \times \mathrm{CIM}-602, \mathrm{~F}_{1} \times \mathrm{FH}-114\right)$ and $\mathrm{F}_{2}$ $\left(\mathrm{F}_{1}\right.$ selfed) of both crosses (TARZAN-1 $\times$ CIM-602 and A$555 \times$ FH-114) were grown under field conditions in the experimental area of the Department of Plant Breeding and Genetics, University of Agriculture Faisalabad, Pakistan. Six basic generations $\left(\mathrm{P}_{1}, \mathrm{P}_{2}, \mathrm{~F}_{1}, \mathrm{BC}_{1}, \mathrm{BC}_{2}\right.$, and $\left.\mathrm{F}_{2}\right)$ of each cross were studied in a separate trial under two watering regimes i.e. normal $(100 \%$ of FC, 10 irrigations) and water stress (50\% of FC, 5 irrigations) following split plot design. Plant to plant distance was maintained $30 \mathrm{~cm}$ and row to row distance $75 \mathrm{~cm}$. At maturity, fully opened bolls were picked and separately ginned with electric ginner. After ginning, lint of each sample was stored in separately labelled bag for fiber analysis and re-conditioned by placing samples in blow room (65\% humidity and $18-20^{\circ} \mathrm{C}$ temperature) using humidifier. The conditioned samples were then analyzed by High Volume Instrument (HVI-900-SA; Zellweger Ltd., Switzerland), available in the Department of Fiber Technology, for fiber length, fiber strength, fiber fineness, fiber maturity and fiber uniformity.

Biometrical analysis: Analysis of variance was performed as outlined by Steel et al. (1997). Generation means analysis (GMA) was performed on all the traits showing significant differences in analysis of variance by following the method as outlined by Mather and Jinks (1982). Means and variances of all six basic populations (P1, P2, BC1, BC2, F1 and F2) were calculated from individual plants pooled over replications. A weighted least square analysis was conducted on the generation means and initially simplest model using parameter $\mathrm{m}$, only was checked for goodness of fit. If chi- square for one parameter model [m] was significant then further complex models [md, mdh, etc.] were tried and tested for goodness of fit. By this method, best model was selected showing significant estimates of all parameters along with non-significant chi-squared value. The higher value parent was always taken as P1 in the model fitting for each trait. Theoretical genetic components of generation means used in the analysis are shown in the Table 1.

Table 1. Coefficients of the mean (m), additive (d), dominance $(h)$, additive $\times$ additive $(i)$, additive $\times$ dominance $(j)$ and dominance $\times$ dominance $(\mathrm{l})$ parameters for the weighted least squares analysis of generation means (Mather and Jinks, 1982).

\begin{tabular}{lcccccc}
\hline Generations & \multicolumn{6}{c}{ Components of Genetic Effects } \\
\cline { 2 - 7 } & $\mathbf{m}$ & {$[\mathbf{d}]$} & {$[\mathbf{h}]$} & {$[\mathbf{i}]$} & {$[\mathbf{j}]$} & {$[\mathbf{l}]$} \\
\hline $\mathrm{P}_{1}$ & 1 & 1.0 & 0.0 & 1.00 & 0.00 & 0.00 \\
$\mathrm{P}_{2}$ & 1 & -1.0 & 0.0 & 1.00 & 0.00 & 0.00 \\
$\mathrm{~F}_{1}$ & 1 & 0.0 & 1.0 & 0.00 & 0.00 & 1.00 \\
$\mathrm{~F}_{2}$ & 1 & 0.0 & 0.5 & 0.00 & 0.00 & 0.25 \\
$\mathrm{BC}_{1}$ & 1 & 0.5 & 0.5 & 0.25 & 0.25 & 0.25 \\
$\mathrm{BC}_{2}$ & 1 & -0.5 & 0.5 & 0.25 & -0.25 & 0.25 \\
\hline
\end{tabular}

Table 2. Coefficients of the D, H, F and $\mathrm{E}$ effects for the weighted least squares analysis of generation variances (Mather and Jinks, 1982).

\begin{tabular}{lcccc}
\hline & \multicolumn{4}{c}{ Components of variation } \\
\cline { 2 - 5 } Generation & D & $\mathbf{H}$ & $\mathbf{F}$ & $\mathbf{E}$ \\
\hline $\mathrm{P}_{1}$ & 0.00 & 0.00 & 0.00 & 1 \\
$\mathrm{P}_{2}$ & 0.00 & 0.00 & 0.00 & 1 \\
$\mathrm{~F}_{1}$ & 0.00 & 0.00 & 0.00 & 1 \\
$\mathrm{~F}_{2}$ & 0.50 & 0.25 & 0.00 & 1 \\
$\mathrm{BC}_{1}$ & 0.25 & 0.25 & -0.5 & 1 \\
$\mathrm{BC}_{2}$ & 0.25 & 0.25 & 0.50 & 1 \\
\hline
\end{tabular}

Heritability: Heritability in narrow sense $\left(\mathrm{h}^{2}{ }_{\mathrm{ns}}\right)$ was calculated by the formula:

$$
\begin{aligned}
& (1)=0.5 \mathrm{D} /(0.5 \mathrm{D}+\mathrm{E}) \\
& (2)=0.5 \mathrm{D} /(0.5 \mathrm{D}+0.25 \mathrm{H}+\mathrm{E})
\end{aligned}
$$

Heritability in the $\mathrm{F}_{\infty}$ generation was calculated by

$$
\mathrm{H}_{\infty}^{2}=\mathrm{D} /(\mathrm{D}+\mathrm{E})
$$

\section{RESULTS}

Fiber length: Analysis of variance showed significant differences among all the fiber quality traits $(p \geq 0.01)$. Highest fiber length was found for $\mathrm{F}_{2}$ generation as compared to $\mathrm{P}_{1}, \mathrm{P}_{2}, \mathrm{~F}_{1}, \mathrm{BC}_{1}$ and $\mathrm{BC}_{2}$ under normal watering regime in both the crosses $(\mathrm{A}-555 \times \mathrm{FH}-114$ and TARZAN-1 $\times$ CIM602) while $P_{2}$ showed maximum fiber length under water stressed conditions. Higher fiber length was found for $\mathrm{F}_{2}$ $(28.1 \pm 0.08)$ followed by $\mathrm{P}_{2} \quad(27.74 \pm 0.093)$ and $\mathrm{P}_{1}$ 
(27.01 \pm 0.47$)$ generations under controlled conditions while $\mathrm{P}_{2}(26.1 \pm 0.21)$ and $\mathrm{F}_{2}(25.42 \pm 0.48)$ under water deficit in cross-1 (A-555 $\times$ FH-114) and in cross-2 (TARZAN-1 $\times$ CIM-602), $F_{2}(27.9 \pm 0.05)$ was at the top in normal environment and generation $\mathrm{P}_{2}(26.28 \pm 0.53)$ under stressed conditions (Fig. 1).

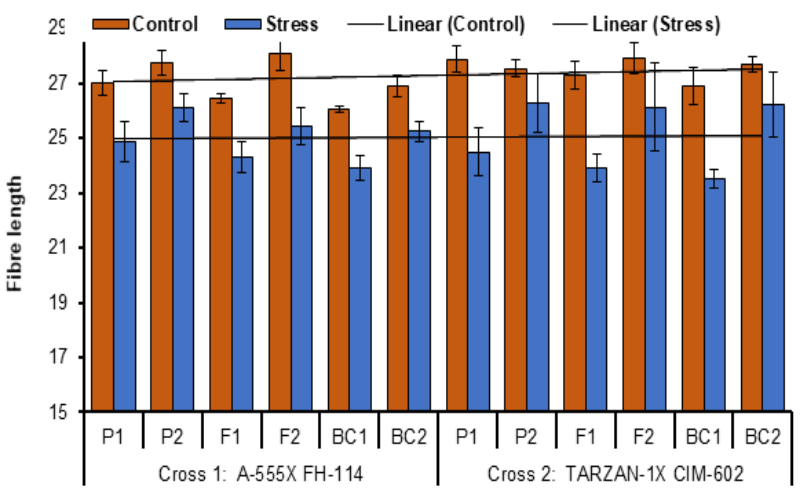

Figure 1. Mean performance of six generations of cotton for fiber length under normal and stress conditions.

For the trait fiber length, additive and non-additive genetic effects were present under normal and drought stress conditions in cross-1(A-555 $\times$ FH-114) and cross-2
(TARZAN-1 × CIM-602) (Table 3 and 4). For fiber length genotypic variance was 0.84 in cross -1 and 0.47 in cross- 2 under normal environment while 0.80 in cross- 1 and 3.76 in cross-2 under stressed conditions. Lower values of genetic advance were observed in both crosses under both watering regimes (Table 5).

Fiber strength: The generation $\mathrm{P}_{2}$ was most promising as compared to $\mathrm{P}_{1}, \mathrm{BC}_{2}, \mathrm{~F}_{1}, \mathrm{~F}_{2}$ and $\mathrm{BC}_{1}$ under normal as well as water deficit in both the crosses $(\mathrm{A}-555 \times \mathrm{FH}-114$ and TARZAN-1 $\times$ CIM-602). Higher fiber strength was found for $\mathrm{P}_{2} \quad(29.1 \pm 0.49)$ followed by $\mathrm{BC}_{1}(26.58 \pm 0.37)$ and $\mathrm{P}_{1}$ $(26.57 \pm 0.30)$ generations under controlled conditions while $\mathrm{P}_{2}(28.41 \pm 0.27)$ and $\mathrm{F}_{2}(26.2 \pm 0.37)$ under water deficit in cross-1 (A-555 $\times$ FH-114) and in cross-2 (TARZAN-1 $\times$ CIM-602), $\mathrm{P}_{2}(28.63 \pm 0.52)$ was at the top in normal environment and $(27.60 \pm 0.31)$ under stressed conditions (Fig.2). Dominant, additive and epistatic genetic effects were important in fiber strength (Table 3) under normal and drought stress conditions was proved fit to data in cross-1(A$555 \times$ FH-114) and cross-2 (TARZAN-1 $\times$ CIM-606) (Table 4). A reasonable amount of genotypic variance 3.59 coupled with high genetic gain (3.96) was observed in cross1 under stressed environment. In cross-2, high genetic advance $(2.24,2.08)$ was supported by high genotypic variance $(1.21,0.95)$ under normal and stressed conditions (Table 5).

Table 3. Genetic effects of fiber fineness (FF), fiber length (FL), fiber strength (FS), fiber maturity (FM) and fiber uniformity (FU) in the crosses A-555 × FH-114 (C1, S1) and TARZAN-1× CIM-602 (C2, S2) under normal and drought conditions in the field.

\begin{tabular}{|c|c|c|c|c|c|c|c|c|}
\hline \multirow[t]{2}{*}{ Trait } & \multirow[t]{2}{*}{ Cross } & \multicolumn{6}{|c|}{ Genetic effect } & \multirow[t]{2}{*}{$X^{2}(d f)$} \\
\hline & & {$[\mathrm{m}]$} & [d] & [h] & [i] & {$[\mathbf{j}]$} & {$[1]$} & \\
\hline \multirow[t]{4}{*}{$\mathrm{FF}$} & $\mathrm{C} 1$ & $4.17 \pm 1.28$ & $0.27 \pm 0.04$ & $-11.30 \pm 1.29$ & $-5.53 \pm 0.54$ & & $5.53 \pm 0.80$ & $3.46(1)$ \\
\hline & $\mathrm{S} 1$ & $5.50 \pm 1.10$ & $0.44 \pm 0.02$ & $-12.10 \pm 1.40$ & $-8.67 \pm 1.09$ & & $4.13 \pm 0.90$ & $2.94(1)$ \\
\hline & $\mathrm{C} 2$ & $3.90 \pm 1.08$ & $0.47 \pm 0.03$ & $9.17 \pm 1.50$ & $4.54 \pm 1.33$ & & $2.70 \pm 1.01$ & $0.07(1)$ \\
\hline & $\mathrm{S} 2$ & $5.02 \pm 1.06$ & $0.53 \pm 0.13$ & $14.70 \pm 1.40$ & $6.86 \pm 1.16$ & & $1.30 \pm 0.40$ & $0.81(2)$ \\
\hline \multirow[t]{4}{*}{ FL } & $\mathrm{C} 1$ & $30.50 \pm 0.57$ & $1.92 \pm 0.67$ & $-3.22 \pm 0.81$ & $-4.90 \pm 1.31$ & $1.32 \pm 0.87$ & & $0.47(1)$ \\
\hline & $\mathrm{S} 1$ & $26.40 \pm 1.07$ & $1.46 \pm 0.09$ & $-2.42 \pm 1.06$ & $-2.51 \pm 0.25$ & $1.22 \pm 0.91$ & & $0.78(1)$ \\
\hline & $\mathrm{C} 2$ & $28.80 \pm 0.46$ & $1.81 \pm 0.55$ & $1.20 \pm 0.85$ & $1.50 \pm 0.77$ & $0.99 \pm 0.25$ & & $0.02(1)$ \\
\hline & $\mathrm{S} 2$ & $18.90 \pm 0.66$ & $1.68 \pm 0.44$ & $1.88 \pm 1.06$ & $1.90 \pm 0.77$ & $1.01 \pm 0.33$ & & $0.05(1)$ \\
\hline \multirow[t]{4}{*}{ FS } & $\mathrm{C} 1$ & $28.24 \pm 1.67$ & $0.56 \pm 0.08$ & $13.10 \pm 1.08$ & $-6.97 \pm 0.87$ & & & 1.61(2) \\
\hline & $\mathrm{S} 1$ & $25.77 \pm 1.44$ & $0.66 \pm 0.17$ & $9.10 \pm 0.86$ & $-2.90 \pm 0.86$ & & & $0.08(2)$ \\
\hline & $\mathrm{C} 2$ & $27.40 \pm 0.51$ & $0.66 \pm 0.18$ & $4.31 \pm 0.68$ & $1.90 \pm 0.56$ & & & $0.31(2)$ \\
\hline & $\mathrm{S} 2$ & $22.10 \pm 1.87$ & $0.46 \pm 0.07$ & $2.10 \pm 1.16$ & $2.39 \pm 1.70$ & & & $0.19(2)$ \\
\hline \multirow[t]{4}{*}{ FU } & $\mathrm{C} 1$ & $78.53 \pm 1.12$ & $1.65 \pm 0.58$ & $14.94 \pm 0.77$ & $11.12 \pm 0.68$ & $5.15 \pm 0.70$ & & $0.27(1)$ \\
\hline & $\mathrm{S} 1$ & $59.23 \pm 0.97$ & $1.25 \pm 0.08$ & $11.54 \pm 0.67$ & $8.19 \pm 0.39$ & $3.44 \pm 0.34$ & & $0.21(1)$ \\
\hline & $\mathrm{C} 2$ & $82.50 \pm 2.17$ & $1.21 \pm 0.22$ & $12.82 \pm 0.76$ & $10.91 \pm 0.79$ & $5.08 \pm 0.60$ & & $0.10(1)$ \\
\hline & $\mathrm{S} 2$ & $57.52 \pm 0.58$ & $1.95 \pm 0.19$ & $12.09 \pm 0.71$ & $9.81 \pm 0.59$ & $5.54 \pm 0.57$ & & $0.53(1)$ \\
\hline \multirow[t]{4}{*}{ FM } & $\mathrm{C} 1$ & $82.11 \pm 1.52$ & $0.71 \pm 0.18$ & $17.44 \pm 2.77$ & $12.52 \pm 1.38$ & $7.11 \pm 2.02$ & & $1.23(1)$ \\
\hline & $\mathrm{S} 1$ & $62.29 \pm 2.58$ & $0.41 \pm 0.11$ & $11.64 \pm 2.56$ & $9.12 \pm 1.06$ & $3.19 \pm 1.02$ & & $1.02(1)$ \\
\hline & $\mathrm{C} 2$ & $73.29 \pm 2.49$ & $0.81 \pm 0.19$ & $21.64 \pm 4.56$ & $12.80 \pm 2.06$ & $6.09 \pm 3.02$ & & $0.75(1)$ \\
\hline & $\mathrm{S} 2$ & $54.59 \pm 2.21$ & $0.47 \pm 0.05$ & $9.64 \pm 3.06$ & $17.20 \pm 2.01$ & $3.21 \pm 0.86$ & & $0.05(1)$ \\
\hline
\end{tabular}

Mean (m), additive (d), dominance (h), additive $\times$ additive (i), additive $\times$ dominance $(\mathrm{j})$ and dominance $\times$ dominance $(\mathrm{l})$. 
Table 4. Components of variation $D$ (additive), $H$ (Dominance), $F$ (Additive $\times$ Dominance) and $E$ (environmental) and heritability (ns, narrow sense and Fo generation) of fiber traits in the crosses A-555 $\times$ FH-114 (C1,S1) and TARZAN-1 $\times$ CIM-602 (C2, S2) under normal and drought conditions in the field.

\begin{tabular}{|c|c|c|c|c|c|c|c|c|}
\hline \multirow[t]{2}{*}{ Traits } & \multirow[t]{2}{*}{ Cross } & \multicolumn{4}{|c|}{ Genetic variance analysis } & \multirow[t]{2}{*}{ Chi. Sq. value } & \multicolumn{2}{|c|}{ Heritability } \\
\hline & & [d] & {$[\mathrm{h}]$} & [f] & [e] & & Ns & $\mathbf{F} \infty$ \\
\hline \multirow[t]{4}{*}{ FL } & $\mathrm{C} 1$ & $0.27 \pm 0.04$ & & & $2.54 \pm 0.30$ & $0.03(4)$ & 0.661581 & 0.79744 \\
\hline & S1 & $0.44 \pm 0.11$ & & & $1.71 \pm 0.20$ & $1.20(4)$ & 0.764469 & 0.87575 \\
\hline & $\mathrm{C} 2$ & $0.47 \pm 0.03$ & & & $3.31 \pm 0.30$ & $0.20(4)$ & 0.690553 & 0.84233 \\
\hline & S2 & $0.53 \pm 0.12$ & & & $1.91 \pm 0.20$ & $0.24(4)$ & 0.748716 & 0.85260 \\
\hline \multirow[t]{4}{*}{ FS } & $\mathrm{C} 1$ & $1.92 \pm 0.67$ & & & $0.01 \pm 0.01$ & $4.04(4)$ & 0.756981 & 0.88321 \\
\hline & S1 & $1.46 \pm 0.09$ & & & $0.03 \pm 0.00$ & $0.07(4)$ & 0.815393 & 0.89588 \\
\hline & $\mathrm{C} 2$ & $1.81 \pm 0.55$ & & & $0.01 \pm 0.07$ & $0.60(4)$ & 0.905104 & 0.98739 \\
\hline & S2 & $1.68 \pm 0.44$ & & & $0.01 \pm 0.06$ & $0.02(3)$ & 0.912949 & 0.98707 \\
\hline \multirow[t]{4}{*}{ FF } & $\mathrm{C} 1$ & $0.56 \pm 0.08$ & & & $2.44 \pm 0.30$ & $0.03(4)$ & 0.631521 & 0.78740 \\
\hline & S1 & $0.66 \pm 0.17$ & & & $1.51 \pm 0.20$ & $1.20(4)$ & 0.746739 & 0.87075 \\
\hline & $\mathrm{C} 2$ & $0.66 \pm 0.18$ & & & $3.41 \pm 0.30$ & $0.20(4)$ & 0.660323 & 0.86103 \\
\hline & S2 & $0.46 \pm 0.00$ & & & $1.71 \pm 0.20$ & $0.22(4)$ & 0.740116 & 0.85720 \\
\hline \multirow[t]{4}{*}{ FM } & $\mathrm{C} 1$ & $10.30 \pm 2.40$ & & & $2.44 \pm 0.30$ & $0.03(4)$ & 0.631521 & 0.78740 \\
\hline & S1 & $8.10 \pm 1.20$ & & & $1.51 \pm 0.20$ & $1.20(4)$ & 0.746739 & 0.87075 \\
\hline & $\mathrm{C} 2$ & $9.06 \pm 2.12$ & & & $3.41 \pm 0.30$ & $0.20(4)$ & 0.660323 & 0.86103 \\
\hline & S2 & $8.50 \pm 1.40$ & & & $1.71 \pm 0.20$ & $0.22(4)$ & 0.740116 & 0.85720 \\
\hline \multirow[t]{4}{*}{ FU } & $\mathrm{C} 1$ & $0.73 \pm 0.20$ & & & $0.25 \pm 0.03$ & $0.70(4)$ & 0.593496 & 0.74489 \\
\hline & S1 & $0.43 \pm 0.10$ & & & $0.33 \pm 0.04$ & $1.43(4)$ & 0.394495 & 0.56578 \\
\hline & $\mathrm{C} 2$ & $1.03 \pm 0.20$ & & & $0.42 \pm 0.06$ & $0.49(4)$ & 0.550802 & 0.71034 \\
\hline & S2 & $0.46 \pm 0.16$ & & & $0.34 \pm 0.04$ & $0.16(4)$ & 0.403509 & 0.57543 \\
\hline
\end{tabular}

Table 5. Genetic components for fiber traits under normal and drought condition in cross-1 and cross-2

\begin{tabular}{|c|c|c|c|c|c|c|c|c|c|c|c|c|c|}
\hline \multirow[t]{2}{*}{ Traits } & \multirow[t]{2}{*}{ Cross\# } & \multicolumn{2}{|c|}{ GV } & \multicolumn{2}{|c|}{ GCV } & \multicolumn{2}{|c|}{ PV } & \multicolumn{2}{|c|}{ PCV } & \multicolumn{2}{|c|}{ EV } & \multicolumn{2}{|c|}{ GA } \\
\hline & & C & $\mathbf{S}$ & C & $\mathbf{S}$ & C & $\mathbf{S}$ & $\mathrm{C}$ & $\mathbf{S}$ & $\mathrm{C}$ & $\mathbf{S}$ & C & $\mathbf{S}$ \\
\hline \multirow[t]{2}{*}{$\overline{\mathrm{FL}}$} & 1 & 0.84 & 0.80 & 3.20 & 3.61 & 0.90 & 0.83 & 3.50 & 3.67 & 0.07 & 0.02 & 0.31 & 1.31 \\
\hline & 2 & 0.47 & 3.76 & 2.49 & 7.73 & 0.53 & 3.83 & 2.65 & 7.80 & 0.06 & 0.07 & 0.83 & 0.03 \\
\hline \multirow[t]{2}{*}{ FS } & 1 & 0.59 & 3.59 & 3.30 & 9.18 & 0.70 & 3.79 & 3.60 & 9.43 & 0.12 & 0.20 & 1.80 & 3.96 \\
\hline & 2 & 1.21 & 0.95 & 4.55 & 4.69 & 1.35 & 1.09 & 4.83 & 5.02 & 0.15 & 0.13 & 2.24 & 2.08 \\
\hline \multirow[t]{2}{*}{ FF } & 1 & 0.32 & 0.17 & 16.20 & 11.06 & 0.30 & 0.18 & 16.40 & 11.42 & 0.01 & 0.01 & 1.90 & 1.18 \\
\hline & 2 & 0.15 & 0.13 & 11.79 & 10.67 & 0.16 & 0.15 & 12.23 & 11.15 & 0.01 & 0.10 & 1.27 & 1.31 \\
\hline \multirow[t]{2}{*}{ FU } & 1 & 7.05 & 10.34 & 3.70 & 4.92 & 9.20 & 10.39 & 4.20 & 4.93 & 2.10 & 0.05 & 7.70 & 7.89 \\
\hline & 2 & 6.60 & 7.03 & 3.77 & 3.96 & 6.65 & 7.08 & 3.78 & 4.20 & 0.04 & 0.05 & 4.79 & 4.38 \\
\hline \multirow[t]{2}{*}{ FM } & 1 & 3.11 & 4.91 & 2.30 & 3.02 & 4.13 & 5.92 & 2.70 & 3.30 & 1.01 & 1.01 & 7.10 & 3.27 \\
\hline & 2 & 3.61 & 2.97 & 2.49 & 2.38 & 4.63 & 3.94 & 2.82 & 2.74 & 1.01 & 0.97 & 3.28 & 5.01 \\
\hline
\end{tabular}

$\mathrm{GV}=$ Genotypic variance, $\mathrm{PV}=$ Phenotypic variance, $\mathrm{GCV}=$ Genotypic coefficient of variance, PCV = Phenotypic coefficient of variance, $\mathrm{EV}=$ Environmental variance, $\mathrm{GA}=$ Genetic advance.

Fiber fineness: $\mathrm{F}_{1}$ was most promising generation as compared to $\mathrm{P}_{1}, \mathrm{P}_{2} \mathrm{BC}_{2}, \mathrm{~F}_{2}$ and $\mathrm{BC}_{1}$ under normal while $\mathrm{P}_{2}$ under water deficit in both the crosses $(\mathrm{A}-555 \times \mathrm{FH}-114$ and TARZAN-1 $\times$ CIM-602). Higher fiber fineness was found for $\mathrm{F}_{1}(3.24 \pm 0.021)$ under controlled conditions in cross-1 (A-555 $\times$ FH-114) and (3.27 \pm 0.03$)$ in cross-2 (TARZAN-1 $\times$ CIM$602)$ under normal while under stressed conditions, $\mathrm{P}_{2}$ (3.56 \pm 0.07$)$ was at the top in cross-1and (3.1 \pm 0.16$)$ in cross2 (Fig. 3). For fiber fineness, model with five parameters [m, $\mathrm{d}, \mathrm{h}, \mathrm{i}, \mathrm{l}$ ( Table 3) under normal and stressed conditions for cross-1(A-555 $\times$ FH-114) and cross-2 (TARZAN-1 $\times$ CIM-
602 was found fit to data. Fiber fineness showed lower genotypic variance along with lower genetic gain under both watering regimes in both crosses (Table 5).

Fiber maturity: In case of fiber maturity, $\mathrm{P}_{2}$ was most promising generation as compared to $\mathrm{P}_{1}, \mathrm{P}_{2} \mathrm{BC}_{2}, \mathrm{~F}_{2}$ and $\mathrm{BC}_{1}$ under normal as well as water limited conditions in both the crosses (A-555 $\times$ FH-114 and TARZAN-1 $\times$ CIM-602). Higher fiber maturity value was found for $\mathrm{P}_{2}(82.37 \pm 0.15)$ under controlled conditions in cross-1 (A-555 $\times$ FH-114) and $(81.45 \pm 0.13)$ in cross-2 (TARZAN-1 $\times$ CIM-602) under normal while under stressed conditions, $\mathrm{P}_{2}(76.37 \pm 0.21)$ was 
at the top in cross-1and $(79.01 \pm 0.18)$ in cross-2 (Fig. 4). For fiber maturity, model with five parameters $[\mathrm{m}, \mathrm{d}, \mathrm{h}, \mathrm{i}, \mathrm{j}]$ (Table 3 and 4) under normal and stressed conditions for cross-1(A-555 $\times$ FH-114) and cross-2 (TARZAN-1 $\times$ CIM602 was found fit to data. High values of genotypic variance $(7.05,10.34)$ and $(6.60,7.03)$ coupled with high genetic advance (7.7, 7.89 and 4.79, 4.38) was found for fiber maturity under normal as well as stressed environment in cross- 1 and cross- 2 respectively (Table 5).

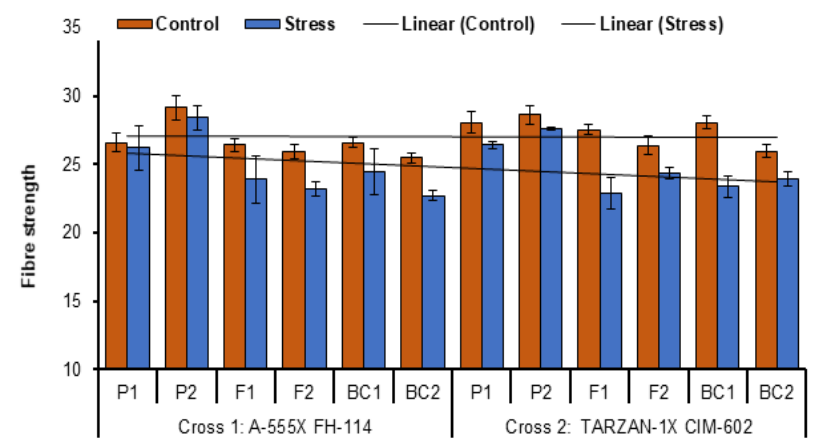

Figure 2. Mean performance of six generations of cotton for fiber strength under normal and stress conditions.

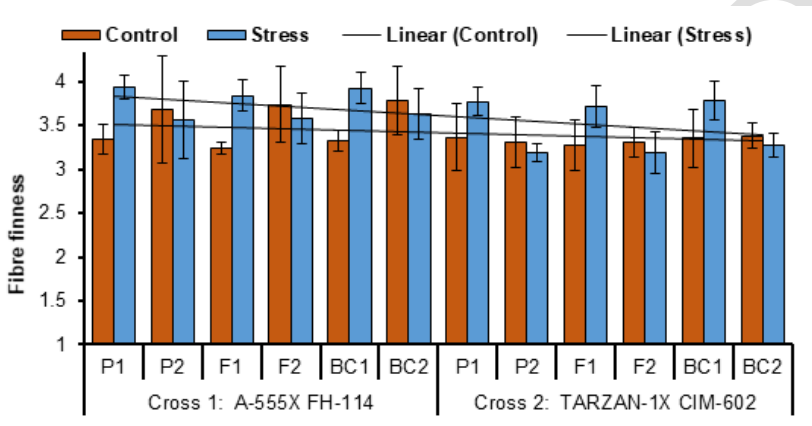

Figure 3. Mean performance of six generations of cotton for fiber fineness under normal and stress conditions.

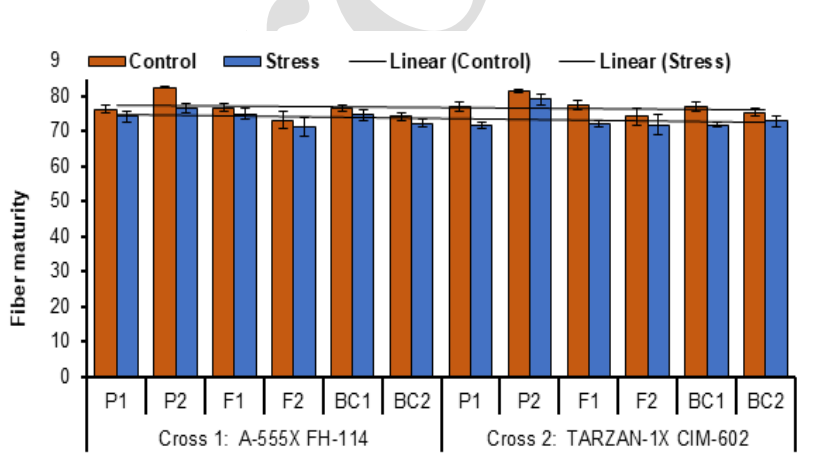

Figure 4. Mean performance of six generations of cotton for fiber maturity under normal and stress conditions.
Fiber uniformity: $\mathrm{F}_{1}$ generation was most capable generation as compared to $\mathrm{P}_{1}, \mathrm{P}_{2} \mathrm{BC}_{2}, \mathrm{~F}_{2}$ and $\mathrm{BC}_{1}$ under normal as well as stress in cross-2 (TARZAN-1 $\times$ CIM-602). In case of cross-1 $\left(\mathrm{A}-555 \times\right.$ FH-114) $\quad \mathrm{F}_{1}$ generation showed maximum uniformity under normal while $\mathrm{P}_{2}$ under water deficit. Higher fiber uniformity was recorded for $F_{1}(79.96 \pm 0.06)$ under controlled conditions in cross-1 (A-555 $\times$ FH-114) and $(80.91 \pm 0.15)$ in cross-2 (TARZAN-1 $\times$ CIM-602) under normal while under stressed conditions, $\mathrm{P}_{2}(69.58 \pm 0.17)$ was at the top in cross -1 and $F_{1}(74.5 \pm 0.14)$ was positioned at top in cross-2 (Fig. 5). For fiber uniformity, model with five parameters $[\mathrm{m}, \mathrm{d}, \mathrm{h}, \mathrm{i}, \mathrm{j}]$ under normal and stressed conditions for cross-1(A-555 $\times$ FH-114) and cross-2 (TARZAN-1 $\times$ CIM-602 was found fit to data (Table 3). Narrow sense heritability (Table 4) estimates for fiber length, strength, fineness and maturity were higher in both crosses while heritability was lower in fiber uniformity. Fiber uniformity also showed higher genotypic variance coupled with high genetic advance in both crosses (Table 5). Residual effects $[\mathrm{m}]$ and $[\mathrm{h}]$ dominance effects were found higher under both watering conditions in both crosses. Additive $x$ additive interaction [i] was found positive for fiber length, strength, fineness, maturity and fiber uniformity.

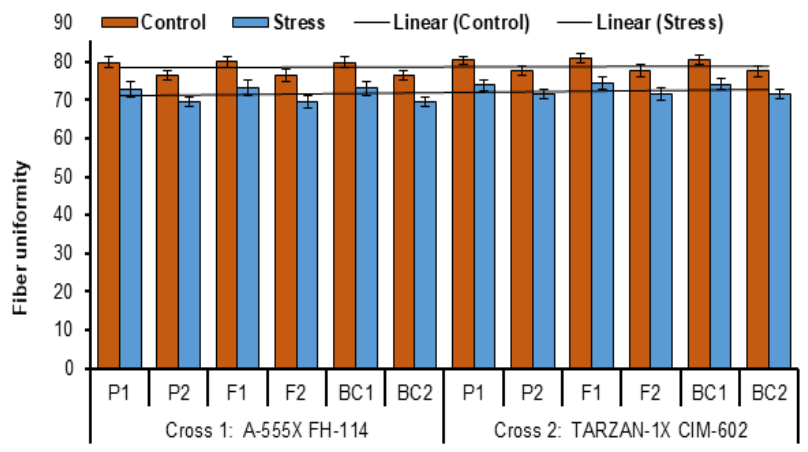

Figure 5. Mean performance of six generations of cotton for fiber uniformity under normal and stress conditions.

\section{DISCUSSION}

Under water stressed conditions, inheritance of fiber traits involved additive along with epistatic type of gene action (Ahmad et al., 2009; Shakoor et al., 2010) while Esmail (2007), Srinivasan et al. (2013), and Refaey and Razek (2013) found both additive and non-additive type of gene action but the magnitude of additive was higher than non-additive genes. Present research concluded that fiber length is found to be controlled by additive, dominant and epistatic kind of gene action (Table 3). Additive, dominance and epistatic genetic effects were found involved in the inheritance of fiber strength and similar results were reported earlier under stressed environment (Ahmad et al., 2009; Shakoor et al., 
2010; Srinivasan et al., 2013). Higher heritability and genetic advance was found in both the lint traits (Table 4 and 5). So, from the present investigations, it is suggested that heterosis breeding may yield fruitful results in this specific plant material and selection at late segregating generations, would be better when allelic combinations are fixed.

Fiber fineness is necessarily required in textile industry, so mere fine fiber will yield quality product. Non- additive with non-allelic interaction type of genes controlled fiber fineness under drought while additive type of genes under normal conditions (Table 3). Previously, Ahmad et al. (2009) and Shakoor et al. (2010) found similar results that correlate with present findings. So, it is predictable that gene expression changes under different environmental conditions hence, it may be due to different background of parents. For the smooth working of cotton spinning and yarn units, uniform length of cotton fiber is the preliminary requirement of textile industry so that troubles of irregular fiber stickiness with machines should be curtailed. Unfortunately, despite the fact that fiber uniformity is an important character yet less attention has been paid in this regard, however, the present study was aimed at exploring the inheritance of fiber uniformity and fiber maturity along with other fiber characters such as fiber length, strength and fineness. Higher narrow sense heritability estimates (Table 5) suggested that selection for fiber uniformity should be delayed up to $5^{\text {th }}$ and $6^{\text {th }}$ segregating generations. The results are more or less similar to Srinivas and Bhadru, 2015. Fiber maturity is an important parameter related to textile industry because fully mature fibers produce good quality yarn and cloth. Keeping in view the importance of this character, the inheritance pattern of the character was found under normal and water scarce conditions and current research work pointed out dominant and additive type of genes in the genetic makeup of fiber maturity with medium to high heritability (Table 4 and 5) so, it is suggested that improvement is possible by breeding and selection.

The contribution of both parents to dominance varies conferring to an attribute. Directional dominance is the utility of the $F_{1}$ mean value to the mid parent value that actually shows the strength of the parent towards dominance (Cukadar and Miller, 1997; Haleem et al., 2010). Magnitude of additive genetic effects was higher than non-additive ones for fiber uniformity in both crosses (Table 3 and 4) so, selection in early segregating generations would be effective. Back to previous research work, similar conclusions were made by (Jagtap, 1986; Mert et al., 2003). It is recommended for cotton breeders to exploit these characters pedigree selection may also be suitable. Same conclusions were drawn in the previous studies for one or other fiber quality trait (Esmail, 2007; Srinivasan et al., 2013; Refaey and Razek, 2013). Genetic variance of almost all the fiber traits was equal to that of phenotypic variance coupled with higher estimates of genetic gain and heritability (Table 5) so, selection could be rewarding in cotton fiber quality improvement program.
Literature available on the inheritance on fiber traits shows that when heritability is high coupled with high genetic advance, mostly genetic and phenotypic variance are equal in magnitude, breeders should go for selection.

Conclusion: From the investigations, it could be concluded that genetic variance in most of the fiber traits was due to dominant gene action. Though, additive gene effects were also involved in the inheritance of some studied fiber quality traits. Biparental mating, recurrent selection and diallel selective mating system might be rewarding to exploit additive and non-additive gene actions for desirable recombinants. Recurrent selection will yield desirable combination through the breakdown of undesirable linkage groups because of presence of dominance alongside epistasis.

\section{REFERENCES}

Ahmad, R.T., T.A. Malik, I. A. Khan and M.J. Jaskani. 2009. Genetic analysis of some morpho-physiological traits related to drought stress in cotton (Gossypium hirsutum). Int. J. Agric. Biol. 11:235-240.

Baloch, M.J. 2004. Genetic variability and heritability studies on some polygenic traits in upland cotton. Pak. J. Sci. Ind. Res. 42:451-454.

Bita, C. and T. Gerats. 2013. Plant tolerance to high temperature in a changing environment: Scientific fundamentals and production of heat stress-tolerant crops. Front. Plant Sci. 4: 273-280.

Cukadar, O.B. and J.F. Miller. 1997. Inheritance of the stay green trait in sunflower. Crop. Sci. 37:150-153.

Desalegn Z., N. Ratanadilok and R. Kaveeta. 2009. Correlation and heritability for yield and fiber quality parameters of Ethiopian cotton (Gossypium hirsutum L.) estimated from 15 crosses. Kasetsart J. Nat. Sci. 43:1-11.

Esmail, R.M. 2007. Genetic analysis of yield and its contributing traits in two intra-specific cotton crosses. J. Appl. Sci. Res. 3:2075-2080.

Government of Pakistan. 2013-14. Economic Survey of Pakistan, Ministry of Finance, Government of Pakistan.

Government of Pakistan. 2016-17. Economic Survey of Pakistan, Ministry of Finance, Government of Pakistan.

Haleem, S.H.M., M.R. Metwali and M.M. Felaly. 2010. Genetic analysis of yield and its components of some Egyptian cotton (Gossypium barbadense L.) varieties. World J. Agric. Sci. 6:615-621.

Imran, M., A. Shakeel, J. Farooq, A. Saeed, A. Farooq and M. Riaz. 2011. Genetic studies of fiber quality parameter and earliness related traits in upland cotton. Adv. Agric. Bot. 3:151-159.

Jagtap, D.R. 1986. Combining ability in upland cotton. Ind. J. Agric. Sci. 56:833-840.

Lambers, H., J.A. Raven, G.R. Shaver and S.E. Smith. 2008. Plant nutrient-acquisition strategies change with soil age. Trends Ecol. Evol. 23:95-103. 
Manivannan, P., C.A. Jaleel, R. Somasundaram and R. Panneerselvam. 2008. Osmoregulation and antioxidant metabolism in drought-stressed Helianthus annuus under triadimef on drenching. Comp. Rend. Biol. 331:418-425.

Mather, K. and J.L. Jinks. 1982. Biometrical Genetics, $3^{\text {rd }}$ Ed. Champman and Hall Ltd. London, UK.

Mert, M., O. Gencer, Y. Akscan and K. Boyac, 2003. Inheritance of yield and yield components in cotton (Gossypium hirsutum L.). Turk. J. Field Crops 8:62-67.

Minhas, R., I.A. Khan, M.S. Anjam and K. Ali. 2008. Genetics of some fiber quality traits among intraspecific crosses of American cotton (Gossypium hirsutum). Int. J. Agric. Biol. 3:44-60.

Mishra, V., K.A. Cherkauer and S. Shukla. 2010. Assessment of drought due to historic climate variability and projected future climate change in the midwestern United States. J. Hydrometeorol. 11:46-68.

Refaey, R.A. and U.A. Razek. 2013. Generation mean analysis for yield, its components and quality characteristics in four crosses of Egyptian cotton (Gossypium barbadense L.). Asian J. Crop Sci. 5:153156.

Saleem, M.A., T.A. Malik and A. Shakeel. 2015. Genetics of physiological and agronomic traits in upland cotton under drought stress. Pak. J. Agri. Sci. 52:317-324.

Shakoor, M.S., T.A. Malik, F.M. Azhar and M.F. Saleem. 2010. Genetics of agronomic and fiber traits in upland cotton under drought stress. Int. J. Agric. Biol. 12:495500.

Singh, P. and G.S. Chahal. 2005. Estimates of additive, dominance and epistatic variation for yield and its component characters in upland cotton (Gossypium hirsutum L.). J. Cotton Res. Dev. 17:135-141.

Soomro, Z.A., M.B. Kumbhar, A.S. Larik, M. Imran and S.A. Brohi. 2010. Heritability and selection response in segregating generations of upland cotton. Pak. J. Agric. Res. 23:1-2.

Srinivas, B. and D. Bhadru. 2015. Estimation of genetic parameters through generation mean analysis for fiber quality traits in upland cotton. SABRAO. J. Breed. Genet. 47:238-247.

Srinivasan, K., R. Rajashekaran and G. Mahalingam. 2013. Genetic analysis for quantitative and quality characters in three single crosses of upland cotton. Not. Sci. Biol. 5:450-453.

Steel, R.G.D., J.H. Torrie and D.A. Dickey. 1997. Principles and procedures of statistics: A biotechnology approach, $3^{\text {rd }}$ Ed. McGraw Hill Book Co., New York, USA.

Walter, P. and D. Ron. 2011. The unfolded protein response: from stress pathway to homeostatic regulation. Sci. 334:1081-1086.

Yuan, Y., T. Zheng, G.W. Zhen, P.J. Ju, Yuan, Y.L. Zhang, T.Z. Guo, and J.J. Pan. 2002. Genetic stability of fiber qualities in upland cotton. Cotton Sci. 14:67-70. 